\title{
Proposal of a production and management index (PMI) for tilapia farms ${ }^{1}$
}

\author{
A. Muniesa, ${ }^{* 2}$ A. L. Rey-Castaño, $\dagger$ I. Ruiz-Zarzuela,* M. Guarín, \\ *Department of Animal Pathology, Faculty of Veterinary Sciences, \\ Instituto Agroalimentario de Aragón, Universidad de Zaragoza-CITA, c/Miguel Servet 177, \\ 50013 Zaragoza, Spain; †Veterinary Pathobiology Group, Faculty of Veterinary Medicine, Universidad Nacional \\ de Colombia, Bogotá, Colombia; and \$Vicerrectoría de Investigación, Universidad de los Andes, Bogotá, Colombia
}

\begin{abstract}
Tilapia is one of the most important species in aquaculture; however, there is no available index to show the performance of a production unit. It is desirable to assess the productivity using indexes, such as the production and management index for shrimps and the European production efficacy factor for broilers. These indexes are based on data production: growth, survival, and feed conversion of a full production cycle. Taking into account these parameters, we propose a production and management index (PMI) for tilapia that is applicable for a specific period of the production cycle. For the construction and validation of the PMI we have used production data from 8,614 monthly records of 2 tilapia farms in Huila Department (Colombia), and because of the complexity of tilapia management, different anomalous situations have been detected and then defined as exceptions. As a result, 419 records were considered
\end{abstract}

extreme values because 1 or more exceptions were met. The value of the PMI varies from 0 (the worst situation) to 3.55 , which reflects high variability. We have constructed a PMI for tilapia as the product of 3 elements to obtain a positive value index. Instead of classic parameters, we had to calculate an adapted version of them: the relative average daily growth, the survival (as a complementary value of the estimated monthly mortality), and a feed conversion ratio index. To assess the utility of the PMI, some comparisons were performed using records from black and red tilapia. We observed significant differences depending on tilapia strain $\left(\mathrm{PMI}_{\text {black }}=1.0248\right.$ vs. $\mathrm{PMI}_{\text {red }}=1.1661$; $P<0.001$ ), age (better values for small fish), and season $\left(\mathrm{PMI}_{\text {rainy }}=1.0847\right.$ vs. $\mathrm{PMI}_{\text {dry }}=1.1011 ; P=$ 0.026). According to these results, we can conclude that the PMI could be a useful tool for tilapia farmers, despite the complexity of the calculation.

Keywords: feed conversion, growth rate, mortality, performance, tilapia

\section{INTRODUCTION}

\footnotetext{
${ }^{1}$ The Ministerio de Educación of Spain is acknowledged for the FPU/MEC doctorate fellowship for Ana Muniesa. The Departamento de Industria e Innovación del Gobierno de Aragón and the Fondo Social Europeo provided financial support to Research Group A35 of Universidad de Zaragoza for their basic running costs. The Ministerio de Agricultura y Desarrollo Rural de Colombia, the Universidad Nacional de Colombia, and Federación de Acuicultores de Colombia (Fedacua) provided financial support to the Veterinary Pathobiology Group of the Universidad Nacional de Colombia. The Universidad de Zaragoza (Spain) is acknowledged for an International Cooperation grant for Marlly Guarín.

${ }^{2}$ Corresponding author: animuni@unizar.es

Received May 5, 2016.

Accepted September 7, 2016.
}

Tilapia (Oreochromis sp.) is one of the most important species in aquaculture; its culture is performed under very variable husbandry, environmental conditions, and management strategies. Commonly, tilapia is considered a disease-tolerant species, but the chance of outbreaks increases under stressful conditions (Watanabe et al., 2002; El-Sayed, 2006). Nowadays, different approaches to control diseases in aquatic populations have been developed in many regions. Current strategies are based on a combination of epidemiological surveillance systems and biosecurity measures to identify and to control risk situations affecting fish populations (MacDiarmid, 2001). Early disease detection could trigger contingency plans to minimize the 
impact on fish health. Surveillance programs allow collecting continuous information about the health status of a population, as well as certain risk factors related to disease (Subasinghe et al., 2004; World Organisation for Animal Health, 2014). In recent years some systems of epidemiological surveillance have been implemented on the basis of productivity changes. The continuous monitoring of production data could be very useful for early detection of emerging diseases (Bayot et al., 2008; Dórea et al., 2013; Wendt et al., 2015). The challenge is to summarize collected data to create an index that allows us to assess normal production conditions and to detect low yields that could be related to health problems. However, we need to realize that the production of tilapia has evolved from artisanal farms with no available data toward intensive farms with recordkeeping systems. Furthermore, indexes designed to estimate the productivity in other species, like shrimps (Sonnenholzner et al., 2004) and broilers (Fuller, 2004), did not work for tilapia. The aims of this study were to propose and to validate a production and management index (PMI) for tilapia farming, which could be useful to assess deviations from normality in a wide range of situations.

\section{MATERIALS AND METHODS}

\section{Data Collection}

Production data were collected from 2 tilapia farms with cages of 81.6 and $244.8 \mathrm{~m}^{3}$ in a dam located in Huila Department (Colombia). The information on 726 cages from 2003 to 2011 was collected for variable periods (usually months or fortnights) with Microsoft Excel (Microsoft, Redmond, WA) data sets used by the companies for production purposes. Data included extrinsic variables such as the season (rainy or dry depending on monthly waterfall); intrinsic variables such as cage size, tilapia variety, and weight; and production variables such as initial population size, animal movements, deaths, and provided feed. From these data other variables were calculated such as population size (taking into account initial population, transferences, captures, and deaths), biomass (as the product of the population size and average weight), and fish density (as ratio between population size and the cage volume)

The original data were cleaned to detect and to correct anomalies, such as abnormal values and logic inconsistencies. The data were collected for producers in different data sheets of the same Excel file using specific templates for each company. These templates lack a robust system to prevent errors. For this reason we found discrepancies between the initial population of a period and the final population of the same cage in the previous one, changes in the reared species or the volume of the cage during the same production cycle, errors in dates, and so on. Once the data were checked, data cleaning was performed, and the inaccurate records were removed from the database; finally, 8,614 records (corresponding to 1,175 production cycles from 726 cages) were exported to Microsoft Access 2010 and IBM SPSS 19.0 for Windows (Armonk, NY: IBM Corp.) to perform further analysis.

\section{Design of a Production and Management Index for Tilapia}

Taking into account previous indexes developed in other species (Fuller, 2004; Sonnenholzner et al., 2004), we have constructed a PMI to obtain a positive value index (PMI $\geq 0)$ as the product of 3 factors: the relative average daily growth (ADGr), the survival (as the complementary value of the estimated monthly mortality $[\mathbf{E M M}]$ ), and a feed conversion ratio index (iFCR) according to the following equation (in which none of the 3 factors can have a negative value):

$$
\mathrm{PMI}_{\text {tilapia }}=(1+\mathrm{ADGr}) \times(1-\mathrm{EMM}) \times \mathrm{iFCR} .[1]
$$

Thus, the values closer to zero will be the worst, and the highest values will be the best ones for this index.

\section{Calculation of Relative Average Daily Growth}

Classic ADG only considers the absolute increment of weight in a period of time, but when we calculated the absolute ADG and compared it with the fish weight (Fig. 1), we observed negative values that can be attributable to a loss of weight or errors in sampling for weight estimation. Furthermore, the values and the variability of the ADG were higher when the weight increased; this fact limits the comparison among different ages, and one of our premises was to obtain an index that was independent of weight.

To solve this problem, we propose to use a relative ADG (ADGr). The ADGr was calculated as the daily increase of the average weight of the animals $\left(\mathbf{W}_{t}\right)$ in a given period, adjusted by the average weight of the animals in the previous period:

$$
\mathrm{ADGr}=\frac{\frac{\mathrm{W}_{\mathrm{t}}-\mathrm{W}_{\mathrm{t}-1}}{\text { period(days) }}}{\mathrm{W}_{\mathrm{t}-1}} .
$$

However, there are 2 situations where the calculation of this component provides nonvalid results, so 2 exclusion rules were defined: negative values of ADGr and ADGr greater than 0.5 (considered outliers). We did not consider the excluded records for further calculations. 




Figure 1. Relationship between absolute ADG and weight.

\section{Calculation of Estimated Monthly Mortality}

Classic mortality is calculated for a full production cycle for a specific period of time. However, data provided correspond to periods of different and not uniform lengths (from 1 to $62 \mathrm{~d}$ ), so in order to normalize the value of survival, we used an estimation of the monthly mortality. The EMM was estimated taking into account the number of deaths in a given period in relation to the population at the beginning of the period and the duration of the period. It was calculated as the cumulative probability of survival during the study period, expressed in days and further adjusted to $1 \mathrm{mo}(30.42=365 / 12)$ :

$\mathrm{EMM}=1-$

$\left(1-\frac{\text { Number of deaths }}{\text { Population at the beginning }}\right)^{\frac{30.42}{\text { duration(days) }}}$.

Two exclusion rules were also defined: anomalous high mortalities $(\geq 0.30)$ and relative high mortalities $(\geq 0.20)$ in records with a short period of time $(\leq 7 \mathrm{~d})$.

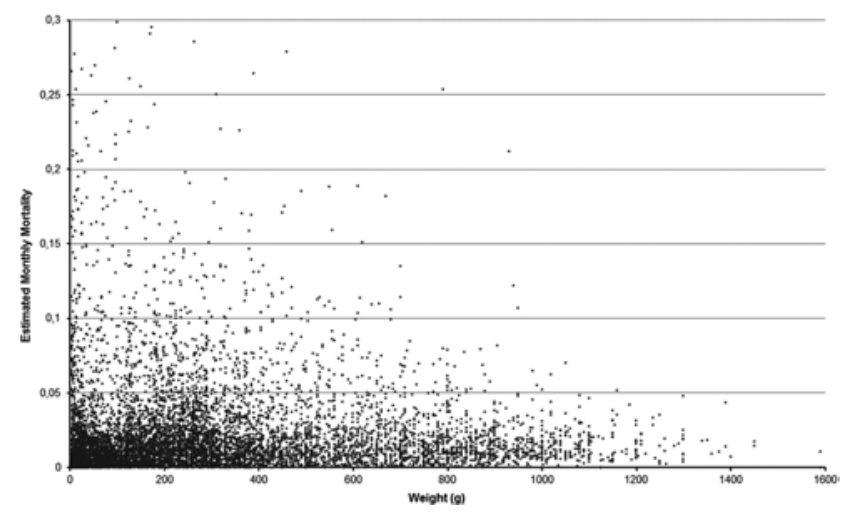

Figure 3. Relationship between relative estimated monthly mortality and weight (applying exclusion rules).

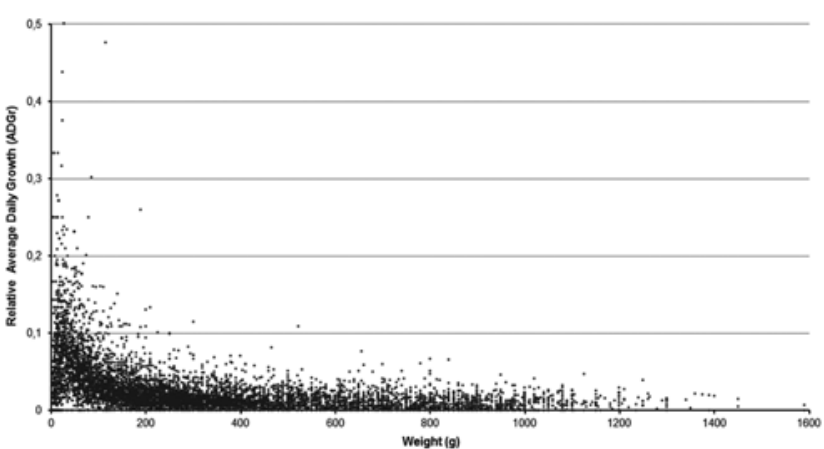

Figure 2. Relationship between relative average daily growth and weight (applying exclusion rules).

\section{Calculation of Index for Feed Conversion Ratio}

The greater challenge for building the PMI was to create a consistent index corresponding to the classic feed conversion rate (FCR) calculated as the ratio between the provided feed and the increment of biomass:

$$
\mathrm{FCR}=\frac{\mathrm{Feed}(\mathrm{kg})}{\text { Biomass }_{\mathrm{t}}(\mathrm{kg})-\text { Biomass }_{\mathrm{t}-1}(\mathrm{~kg})} \text {. }
$$

However, we need to get an index related to FCR (iFCR) whose magnitude is similar to the other 2 components of the PMI (Eq. [1]). The values of ADGr can vary from 0 to 0.5 (Fig. 2), whereas the theoretical values of EMM should be between 0 and 1, but in our proposal some values have been excluded, and the maximum value will be 0.3 (Fig. 3).

Therefore, to build the iFCR, we need to carry out some transformations and to analyze the obtained results. We describe step by step the different transformations that we performed to solve the observed situations, which usually do not occur in standardized management systems such as poultry and shrimp production:

1. Initially, the FCR (Fig. 4) was normalized with a logarithmic transformation $\log _{10}(\mathrm{FCR})$, and the first problem to solve was the negative values obtained with FCR less than 1 . An



Figure 4. Relationship between feed conversion ratio and weight (extreme values excluded). 




Figure 5. Relationship between $\log _{10}(\mathrm{FCR}+1)$ and weight (excluded values of $\mathrm{FCR} \leq-1)$. $\mathrm{FCR}=$ feed conversion ratio.

adjustment adding the unit to FCR was performed. So we used the value of $\log _{10}(\mathrm{FCR}+1$; Fig. 5), but if FCR $\leq-1$, the proposed transformation was not possible (611 records), and the result was questionable when $\mathrm{FCR}=0$ (i.e., because of the absence of feed consumption; 181 records). On the other hand, we obtained 76 records with negative values (corresponding to values of FCR between 0 and -1 , both excluded).

2. We observed that values after this transformation were less than 1 in most cases, so the best values of FCR correspond to the values closer to zero (the proposed target). For this reason, we decided to work with the inverse value: $1 /$ $\log _{10}(\mathrm{FCR}+1)$. Figure 6 shows a distribution similar to that in Fig. 5 with a different scale, but unfortunately, this new approach was not valid for values of FCR equal to zero.

3. The next problem was that the resulting values were so far from the unit (even more than 30) and the factor excessively influenced the PMI calculation, so it was decided to work with the square root of the previous value. However, now, the records with negative values in the

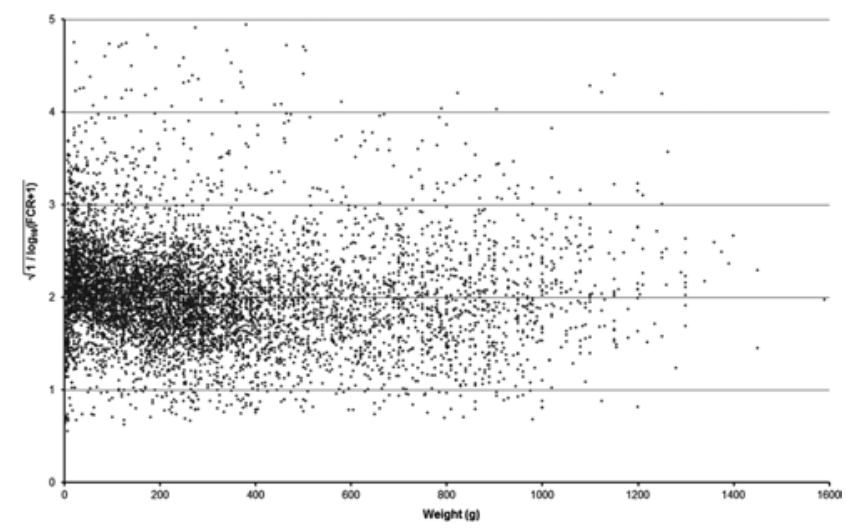

Figure 7. Relationship between square root of $1 / \log _{10}(\mathrm{FCR}+1)$ and weight (excluded values of FCR $\leq 0$ ). FCR $=$ feed conversion ratio.

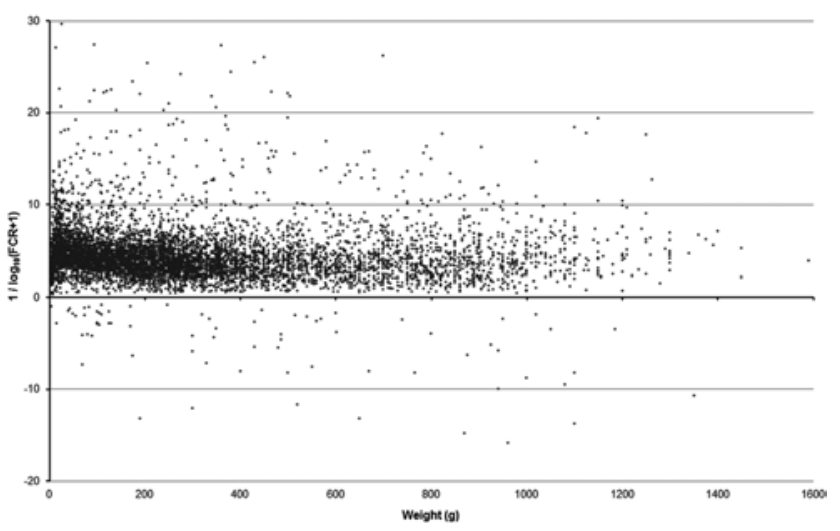

Figure 6. Relationship between relative $\log _{0}^{1}(\mathrm{FCR}+1)$ and weight (excluded values of $\mathrm{FCR} \leq-1$ and $\mathrm{FCR}=0$ ). $\mathrm{FCR}=$ feed conversion ratio.

previous transformation were not valid for calculation (181 records; Fig. 7).

4. In spite of this adjustment, the value still showed excessive weight in the PMI, so we chose to calculate the relative value of the same expression calculated to a neutral value of FCR $(\mathrm{FCR}=1)$. Once simplified, the resulting expression was as follows (although it is only calculable for values of FCR greater than zero):

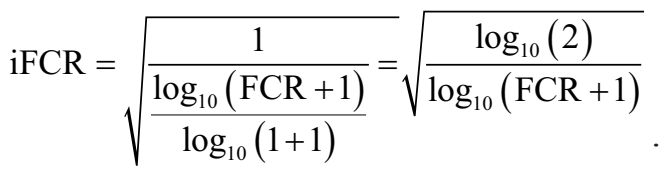

Most of the results for iFCR are between 0 and 2 (Fig. 8), so the initial requirement is fulfilled.

Using Eq. [5], it was not possible to calculate iFCR for $10.1 \%$ of records $(868$ of 8,614$)$ because of 1 or more of the following circumstances:

1. $\left(\right.$ Biomass $_{\mathrm{t}}-$ Biomass $\left._{\mathrm{t}-1}\right)<0$ : This situation corresponds to a decrease in biomass that can be produced by a decrease in the average

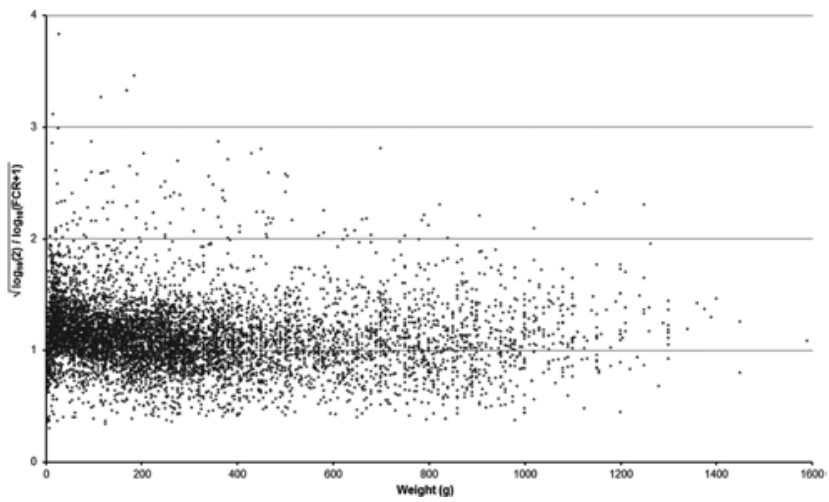

Figure 8. Relationship between preliminary iFCR and weight (excluded values of FCR $\leq 0$ and 3 extreme values of $i F C R) . F C R=$ feed conversion ratio; $\mathrm{iFCR}=\mathrm{FCR}$ index. 
Table 1. Different scenarios for calculation of the feed conversion ratio (FCR)

\begin{tabular}{lcc}
\hline \hline Scenario & Feed $>0$ & Feed $=0$ \\
\hline$\Delta$ Biomass $>0$ & FCR $>0$ & FCR $=(+) 0$ \\
$\Delta$ Biomass $=0$ & FCR $=x / 0=\infty$ & FCR $=0 / 0$ \\
$\Delta$ Biomass $<0$ & FCR $<0$ & FCR $=(-) 0$ \\
\hline
\end{tabular}

weight of the fish, excessive mortalities, and/ or output movements of fish.

2. (Biomass $_{\mathrm{t}}-$ Biomass $\left._{\mathrm{t}-1}\right)=0$ : The biomass remains constant (either the average weight remains constant during the studied period, or the increase in average weight is counteracted by the mortality of the period), and therefore, FCR is not calculable because the denominator is zero. It is an infrequent situation, but it should be considered.

3. Feed consumption $=0$ : This can be due to food restriction associated with movements of fish or can occur when feed management is based on only primary production.

Different scenarios for calculating FCR are summarized in Table 1. Only in the first combination (feed $>0$ and $\triangle$ Biomass $>0$ ) do the formulas for FCR and iFCR work fine, and a range of values that was obtained in 5 subranges based on FCR values was established (be careful that the upper limit of FCR corresponds to the lower limit of iFCR and vice versa):

1. Excessive indicates $\mathrm{FCR}(0,0.1]$ and $\mathrm{iFCR}$ $[2.697, \approx 8.346)$. The upper limit of iFCR was calculated using a FCR equal to 0.01 (the maximum value recorded in our study was 0.012 ), and we decided to consider the records of this category as extreme values because the FCR value was unacceptably low, and they were discarded in further analysis (17 records).

2. Good indicates FCR $(0.1,1]$ and $\mathrm{iFCR}[1,2.697)$.

3. Intermediate indicates FCR $(1,9]$ and iFCR $[0.549,1)$.

4. Bad indicates FCR $(9,50]$ and $\operatorname{iFCR}[0.420$, 0.549).

5. Dreadful indicates FCR $>50$. The highest value for FCR was 379.6 (corresponding to a high feed consumption in a very short period of time), and even with extreme values like this, the value of iFCR is reasonable (0.342).

However, it is necessary to propose alternative formulas for the other scenarios described in Table 1:

1. $\mathrm{FCR}=+0$. This is the most favorable situation since biomass increases without feed admin-
Table 2. Equations proposed for calculation of the feed conversion ratio (FCR) and the FCR index (iFCR)

\begin{tabular}{|c|c|c|c|c|c|c|c|}
\hline$\Delta$ Biomass & Feed & FCR & $\begin{array}{l}\text { Formulas } \\
\text { for } \mathrm{FCR}^{1}\end{array}$ & \multicolumn{4}{|c|}{ Formulas for iFCR } \\
\hline \multirow[t]{3}{*}{$>0$} & $>0$ & $>0$ & Feed & \multicolumn{4}{|c|}{$\log _{10}(2)$} \\
\hline & & & $\Delta$ Biomass & \multirow{2}{*}{\multicolumn{4}{|c|}{$\sqrt{\log _{10}(\mathrm{FCR}+1)}$}} \\
\hline & 0 & $=(+) 0$ & 0.1 & & & & \\
\hline \multirow[t]{2}{*}{$=0$} & $>0$ & $=\mathrm{x} / 0$ & EMFR $\times 97+9$ & & & & \\
\hline & $=0$ & $=0 / 0$ & 9 & & & & \\
\hline \multirow[t]{4}{*}{$<0$} & $>0$ & $<0$ & Feed & & $\log _{10}$ & $(2)$ & \\
\hline & & & $\Delta$ Biomass & \multirow{3}{*}{$\log _{10}$} & \multirow{3}{*}{$250 \sqrt[3]{ }$} & 1 & \multirow{3}{*}{+1} \\
\hline & $=0$ & $=(-) 0$ & Biomass $_{\mathrm{t}-1}$ & & & $\frac{1}{\mathrm{FCR}}$ & \\
\hline & & & $\overline{\Delta \text { Biomass }}$ & & & & \\
\hline
\end{tabular}

${ }^{1} \mathrm{EMFR}=$ estimated monthly feeding rate.

istration (based on only primary production). In this case, the iFCR is not calculable, and we decided to assign the FCR to the lower limit of the subrange good, 0.1 .

2. $\mathrm{FCR}=\mathrm{x} / 0$. In this case, it is not possible to calculate the FCR, and it is like the bad scenario (or even worse) since fish did not grow but were feeding. So the value of the estimated monthly feeding rate (EMFR) was calculated as



Statistical analysis shows that the values of the EMFR were between 0 and 3, and after different simulations we opted to assign the FCR a value proportional to the EMFR in the bad and dreadful range (9, 300], so we estimated the FCR with

$$
\mathrm{FCR}=\mathrm{EMFR} \times \frac{300-9}{3}+9=\mathrm{EMFR} \times 97+9 .
$$

3. $\quad \mathrm{FCR}=0 / 0$. This situation is not as bad as previous one since although the fish did not grow, at least they did not eat food. For that reason, we decided to use these records to cut off values between the subranges intermediate and bad (Table 1). Thus, in this case, the FCR is 9 (and iFCR equal to 0.549). Additionally, records corresponding to periods less than $15 \mathrm{~d}$ were excluded because they are not representative $(n=165)$.

4. FCR $<0$. In this situation, the FCR could be calculated using the Eq. [2], but the iFCR could not be calculated by Eq. [7]. As an alternative equation, we propose Eq. [8], obtained by using the trial and error method, and 
Table 3. Exclusion rules for registers to calculate the production and management index (PMI)

\begin{tabular}{llr}
\hline \hline Criteria $^{1}$ & & \multicolumn{1}{c}{ Cause of exclusion } \\
\hline ADGr $<0$ & Loss of weight & 52 \\
ADGr $\geq 0.5$ & Growth rate too high & 2 \\
EMM $\geq 0.30$ & Excessive estimated mortality & 41 \\
EMM $\geq 0.20$, period $\leq 7 \mathrm{~d}$ & Excessive estimated mortality in a nonrepresentative period of time & 16 \\
FCR $>50$ & FCR too high & FCR too low \\
$0.1>$ FCR $>0$ & Noncalculable FCR and period too short \\
Biomass $=0$, feed $=0$, period $\leq 15 \mathrm{~d}$ & EMFR too high (equivalent to a daily feeding rate greater than $10 \%$ of biomass) & 14 \\
EMFR $>3$ & Fish density too high & 18 \\
Density $>500 \mathrm{fish} / \mathrm{m}^{3}$, biomass $>200 \mathrm{~kg} / \mathrm{m}^{3}$ & Fish density too low & 0 \\
Density $<50 \mathrm{fish} / \mathrm{m}^{3}$, biomass $<10 \mathrm{~kg} / \mathrm{m}^{3}$ & Fish density too low & 8 \\
Density $<100 \mathrm{fish} / \mathrm{m}^{3}$, biomass $<1 \mathrm{~kg} / \mathrm{m}^{3}$ & Changes in population size & 9 \\
Fish movements & & 105 \\
\hline
\end{tabular}

${ }^{1} \mathrm{ADGr}=$ relative average daily growth; EMM = estimated monthly mortality; FCR = feed conversion ratio; EMFR = estimated monthly feeding rate.

it provides values from 0.302 to 0.510 for the negative values of the FCR. It is an overlapping range with values of the iFCR previously described in subranges bad and dreadful:

$$
\mathrm{iFCR}=\sqrt{\frac{\log _{10}(2)}{\log _{10}\left(250 \sqrt[3]{\left|\frac{1}{\mathrm{FCR}}\right|}+1\right)}}
$$

5. $\quad \mathrm{FCR}=-0$. This case occurs when a decrease in biomass is seen in the absence of feed administration, so the FCR is not calculable. Therefore, we propose that in this case the inverse of the relative variance of the biomass can be used; a negative value will be obtained, so we have to apply Eq. [8] for the calculation of the iFCR:

$$
\mathrm{FCR}=\frac{\text { Biomass }_{\mathrm{t}-1}}{\text { Biomass }_{\mathrm{t}}-\text { Biomass }_{\mathrm{t}-1}} .
$$

Table 2 summarizes the different situations for calculating the iFCR, and Fig. 9 shows the results of applying them to the data in our study after applying

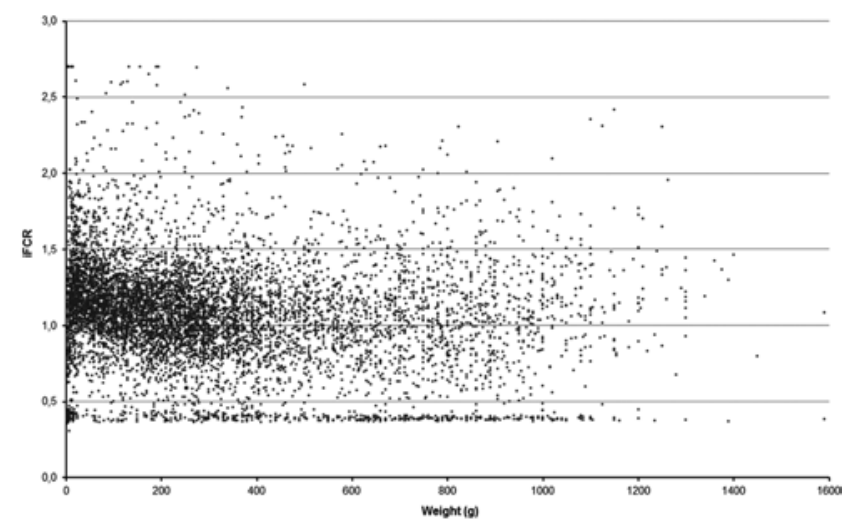

Figure 9. Relationship between iFCR and weight (applying exclusion rules). $\mathrm{iFCR}=$ feed conversion ratio index. some exclusion rules described in Table 3. Some of these rules have been previously described, and additionally, we performed a statistical analysis of fish densities to discard records with too high or too low fish densities ( 8 and 19 records, respectively). We also excluded 98 records with fish movements (inputs or outputs).

\section{Statistical Methods}

Qualitative variables were described with frequencies and quantitative variables using mean, median, $\mathrm{SD}$, minimum, maximum, and a $\mathrm{CI}\left(\mathrm{CI}_{95 \%}\right)$ based on the values of percentiles 2.5 and 97.5 . Normality was checked with the Kolmogorov-Smirnov test. The mean comparison of quantitative variables compatible with a normal distribution was performed with Student's $t$ test (2 means) or ANOVA (more than 2 means). Differences between categories were checked with Duncan's test. When the distribution was not normal, the alternative nonparametric test was used instead (Mann-Whitney U and Kruskal-Wallis tests).

\section{RESULTS}

\section{General Description of Data}

Most of the records corresponded to the rainy season $(69.3 \%)$, and the rest corresponded to dry season $(30.7 \%)$. Three varieties of tilapia were found: black (Chitralada), red, and spotted, but additionally, in some cases black and red tilapias were mixed in the same cage. Table 4 shows that most of the records correspond to black and red tilapias, and the average weights were significantly different. 
Table 4. Weight (g) stratified by tilapia variety

\begin{tabular}{|c|c|c|c|c|c|c|c|c|c|}
\hline Variety & $n$ & $\%$ & Mean $^{1}$ & SD & Median & Minimum & \multicolumn{2}{|c|}{$\mathrm{CI}_{95 \%}$} & Maximum \\
\hline Black & 4,476 & $52.0 \%$ & $426.9^{\mathrm{a}}$ & 315.1 & 365.0 & 2 & 11.0 & $1,085.0$ & 1,590 \\
\hline Red & 3,881 & $45.1 \%$ & $156.8^{\mathrm{c}}$ & 136.6 & 130.0 & 2 & 4.0 & 453.0 & 1,100 \\
\hline Spotted & 143 & $1.7 \%$ & $305.9^{\mathrm{b}}$ & 259.0 & 271.0 & 2 & 3.0 & 903.4 & 1,035 \\
\hline Mixed & 114 & $1.3 \%$ & $280.5^{\mathrm{b}}$ & 124.7 & 274.0 & 6 & 55.9 & 544.0 & 850 \\
\hline Total & 8,614 & $100 \%$ & 301.3 & 280.9 & 220.0 & 2 & 6.0 & 1000.0 & 1590 \\
\hline
\end{tabular}

${ }^{\mathrm{a}-\mathrm{c} D}$ Different superindexes in the same column show significant differences comparing pairs of results with the Mann-Whitney $\mathrm{U}$ test.

${ }^{1}$ Significance of the Kruskal-Wallis test, $P<0.001$.

\section{Calculation of Relative Average Daily Growth}

As we can observe in Fig. 2, the ADGr values were independent of the weight, and the variability was higher at lower weights. Regarding the 2 exclusion rules, we detected 52 records with negative values of ADGr and 2 records where ADGr was greater than 0.5.

\section{Calculation of Estimated Monthly Mortality}

The maximum mortality rates are related to lower weights that correspond to the initial production stages (Fig. 3). From final data some records were excluded, those corresponding to anomalously high mortalities ( $\geq 0.30 ; 41$ records) and relatively high mortalities $(\geq 0.20)$ in records with a short period of time ( $\leq 7 \mathrm{~d} ; 16$ records).

\section{Calculation of Index for Feed Conversion Ratio}

In our study, the variability of FCR was very high, between $-6,592.3$ and 1,863.8. Figure 4 shows the values of FCR related to weight, excluding the extreme values established as FCR $\leq-500(n=9)$ and FCR $\geq 500(n=1)$.

Using the logarithmic transformation of FCR (Eq. [5]), a total of 868 records were not valid. When we applied alternative formulas (Eq. [6] to [9]) designed for specific scenarios, the number of excluded records was reduced by half, and only 419 records were excluded according to 1 or more criteria. Finally, the range of the iFCR results was between 0.303 and 2.697.



Figure 10. Histogram of production and management index values.

\section{Evaluation of the PMI}

The PMI calculated for valid records $(n=8,195)$ had an average value of 1.0898 and a SD of 0.3700 . The median (1.0866) was closer to the mean, and the range was between 0.2633 and 3.5495 .

Figure 10 shows the distribution of the PMI across 14 categories (created according to Sturges, 1926); however, the significance of the Kolmogorov-Smirnov test indicates that the distribution is not normal $(p<0.001)$, probably because of the concentration of values around 0.3 (Fig. 11) as a consequence of adjustments in the calculation of the iFCR to avoid too low values.

We have assessed PMI considering 3 factors: tilapia variety, weight, and season. According to variety, PMI average values were significantly better in red tilapias (1.166) compared with black ones (1.025; Table 5).

Table 6 shows the means of PMI for the smallest $(\leq 20 \mathrm{~g})$ and largest $(\geq 1,000 \mathrm{~g})$ fish were not different between tilapia varieties. For the other weight categories, PMI values were consistently better for red tilapias, and in both cases, the value decreased progressively from 20 to $49 \mathrm{~g}$, although in the heaviest categories it improved slightly.

Finally, PMI values were compared between seasons, with the PMI means being significantly better during the dry season (Table 7). Figure 12 shows the evolution of mean PMI during the studied period for black and red tilapias; the best results were obtained during 2007, and since that year, the average values have decreased.

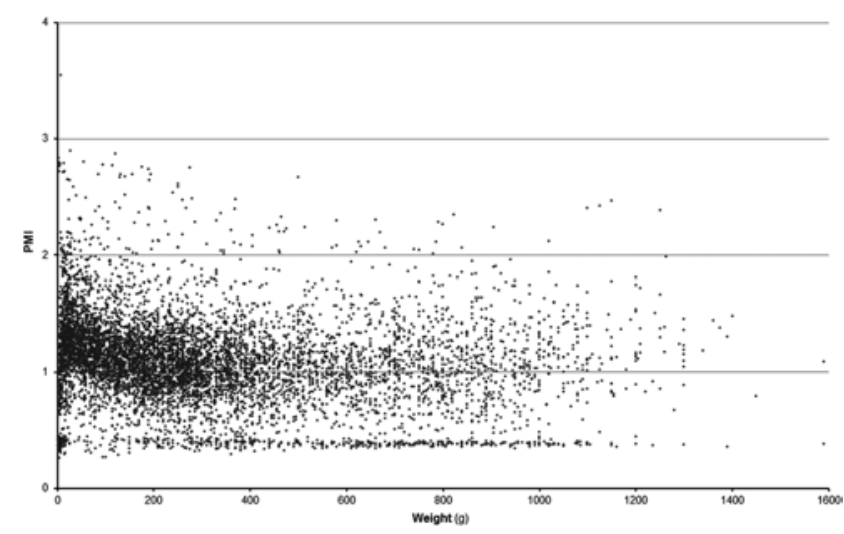

Figure 11. Relationship between production and management index and weight. 
Table 5. PMI stratified by tilapia varieties

\begin{tabular}{|c|c|c|c|c|c|c|c|c|}
\hline \multirow{2}{*}{$\begin{array}{l}\text { Variety } \\
\text { Black }\end{array}$} & \multirow{2}{*}{$\begin{array}{c}n \\
4,288\end{array}$} & \multirow{2}{*}{$\frac{\text { Mean }^{1}}{1.0248}$} & \multirow{2}{*}{$\begin{array}{c}\text { SD } \\
0.3759\end{array}$} & \multirow{2}{*}{$\begin{array}{l}\text { Median } \\
1.0243\end{array}$} & \multirow{2}{*}{$\begin{array}{c}\text { Minimum } \\
0.2672\end{array}$} & \multicolumn{2}{|c|}{$95 \% \mathrm{CI}$} & \multirow{2}{*}{$\frac{\text { Maximum }}{2.832}$} \\
\hline & & & & & & 0.3693 & 1.8266 & \\
\hline Red & 3,660 & 1.1661 & 0.3493 & 1.1437 & 0.2633 & 0.4028 & 2.0158 & 3.550 \\
\hline Total & 7,948 & 1.0898 & 0.3706 & 1.0894 & 0.2633 & 0.3758 & 1.9144 & 3.550 \\
\hline
\end{tabular}

${ }^{1}$ Significance of Mann-Whitney U test, $P<0.001$.

\section{DISCUSSION}

Aquaculture is one of the food-producing sectors in the world with a fast growth rate. Currently, the farming of tilapias and other cichlid species is the most widespread type of aquaculture in the world, and it represents an important proportion of global aquaculture production (Food and Agriculture Organization of the United Nations, 2014). The expansion and intensification of aquaculture activities over the last $30 \mathrm{yr}$ have revealed the emergence of health problems as a major threat to aquaculture development (Subasinghe, 2005). The international opening up of trade has accelerated the accidental entry and dissemination of pathogens into fish populations and geographic areas previously free of these pathogens, so they could cause serious environmental and socioeconomic consequences, especially to international trade (Bondad-Reantaso and Subasinghe, 2008).

Also, it is important to identify, to reduce, or to eliminate risk factors related to disease outbreaks. These factors include water quality, handling conditions of the animals, feeding practices, stocking densities, etc.; the lack of knowledge about these risk factors makes the prediction of disease patterns and the design of approaches for prevention and control difficult (Hedrick, 1998; Georgiadis et al., 2001).

In our experience, disease in tilapia farms is expressed as a subclinical process in most cases, and it is only detectable as a delay in growth and decrease in productivity. Thus, we choose this kind of variable to build the PMI, with the aim to include it in a future syndromic alert system for tilapia. The same approach was used by Bayot et al. (2008) for the early detection of shrimp epidemics at the regional level using a platform called the Epidemiological Alert System and Aquaculture Management based on an index of production management design by Sonnenholzner et al. (2004).

Currently, indexes developed for other species (Fuller, 2004; Sonnenholzner et al., 2004) are calculated at the end of the production cycle because cycles are relatively short (40 to $60 \mathrm{~d}$ for broilers and 90 to $140 \mathrm{~d}$ for shrimps); however, the production cycles of tilapia could range between 4 and 8 mo (El-Sayed, 2006). Therefore, the calculation of this PMI is complex since the production cycle of tilapia is long and many factors should be taken into account (Georgiadis et al., 2001), but the formulas could easily be implemented in a data sheet or a database.

Mortality (or survival) and average weight gain are easy to calculate for a population; however, the calculation of the FCR is difficult if we need to take into account early mortalities, different feeding strategies, and so on. In this way, Dersjant-Li et al. (2014) proposed a modification of the index developed by Fuller (2004) using an adjusted FCR to solve this problem. In our index, we have a similar problem, and the modification of FCR was the critical issue of our work. Our proposal allows considering different husbandry situations as growth without feed supplementation, a very common situation in tilapia production (Watanabe et

Table 6. Production and management index stratified by tilapia varieties and weight categories

\begin{tabular}{|c|c|c|c|c|c|c|c|c|c|}
\hline \multirow[b]{2}{*}{ Item } & \multicolumn{4}{|c|}{ Black tilapia } & \multicolumn{4}{|c|}{ Red tilapia } & \multirow[b]{2}{*}{$P$-value } \\
\hline & $n$ & Mean & SD & Median & $n$ & Mean & $\mathrm{SD}$ & Median & \\
\hline \multicolumn{10}{|l|}{ Weight } \\
\hline$\leq 20 \mathrm{~g}$ & 136 & $1.1385^{\mathrm{b}}$ & 0.5853 & 1.0292 & 448 & $1.0894^{\mathrm{c}}$ & 0.4999 & 1.1662 & 0.360 \\
\hline $20-49 \mathrm{~g}$ & 202 & $1.2495^{\mathrm{a}}$ & 0.3360 & 1.2374 & 484 & $1.3509^{\mathrm{a}}$ & 0.3401 & 1.3028 & 0.001 \\
\hline $50-119 \mathrm{~g}$ & 416 & $1.1262^{\mathrm{b}}$ & 0.3708 & 1.0846 & 750 & $1.2476^{\mathrm{a}, \mathrm{b}, \mathrm{c}}$ & 0.2641 & 1.2018 & $<0.001$ \\
\hline $120-299 \mathrm{~g}$ & 1,054 & $1.0373^{\mathrm{c}, \mathrm{d}}$ & 0.3264 & 1.0305 & 1,453 & $1.1175^{\mathrm{c}}$ & 0.3014 & 1.0826 & $<0.001$ \\
\hline $300-599 \mathrm{~g}$ & 1,163 & $0.9848^{\mathrm{d}, \mathrm{e}}$ & 0.3430 & 0.9802 & 498 & $1.0739^{\mathrm{c}}$ & 0.3437 & 1.0570 & $<0.001$ \\
\hline $600-999 \mathrm{~g}$ & 1,103 & $0.9549^{\mathrm{e}}$ & 0.3897 & 0.9710 & 22 & $1.1418^{\mathrm{b}, \mathrm{c}}$ & 0.2988 & 1.0783 & 0.021 \\
\hline$\geq 1,000 \mathrm{~g}$ & 214 & $1.0591^{\mathrm{c}}$ & 0.4318 & 1.1176 & 5 & $1.3124^{\mathrm{a}, \mathrm{b}}$ & 0.7224 & 1.2809 & 0.376 \\
\hline Total & 4,288 & 1.0248 & 0.3759 & 1.0243 & 3,660 & 1.1661 & 0.3493 & 1.1437 & $<0.001^{1}$ \\
\hline$P$-value & & $<0.001^{2}$ & & & & $<0.001^{2}$ & & & \\
\hline
\end{tabular}

${ }^{\mathrm{a}-\mathrm{e}}$ Superindexes in the same column show significant differences comparing pairs of results with the Mann-Whitney U test.

${ }^{1}$ Significance of the Mann-Whitney U test.

${ }^{2}$ Significance of the Kruskal-Wallis test. 
Table 7. Production and management index stratified by season (using only black and red tilapias)

\begin{tabular}{|c|c|c|c|c|c|c|c|c|}
\hline Variety & $n$ & Mean $^{1}$ & $\mathrm{SD}$ & Median & Minimum & \multicolumn{2}{|c|}{$\mathrm{CI}_{95 \%}$} & Maximum \\
\hline Rainy & 5,455 & 1.0847 & 0.3787 & 1.0856 & 0.2633 & 0.3732 & 1.9216 & 3.5495 \\
\hline Dry & 2,493 & 1.1011 & 0.3522 & 1.0944 & 0.2846 & 0.3815 & 1.8854 & 2.7735 \\
\hline Total & 7,948 & 1.0898 & 0.3706 & 1.0894 & 0.2633 & 0.3758 & 1.9144 & 3.5500 \\
\hline
\end{tabular}

${ }^{1}$ Significance of Mann-Whitney U test, $P=0.026$.

al., 2002). However, in other species, like salmonids, this situation is infrequent, so a simplified index could be used, and most of the exception rules related to Eq. [5] could be avoided.

Summarizing, the classic production index does not allow us to compare the performance of tilapia cages in a period of time. Data provided by the fish farmers correspond to variable periods of time, whereas the lengths of the production cycle of broilers and shrimps are very similar across all companies. These cycles are relatively short, and the producers can easily compare full production cycles with simple indexes and parameters; however, in tilapia the production cycle is very long, and we need a normalized parameter to compare a specific period of time, discarding the effect of age/weight in the results. Another important problem is related to feeding practices. In the case of broilers it is very easy to calculate FCR in a full production cycle (as the quotient of final weight and feed provided; initial weight is discarded because it is very low). For shrimps, the management practices are variable (from continuous feeding in intensive systems to nonfeeding in extensive systems based on primary production of the pond); as a consequence, the FCR is not useful for shrimp farms, and average production by hectare is used. In tilapia the feeding management changes a lot depending on age, environmental conditions, water temperature, and primary production of the pond; the classic FCR is not valid, and a set of formulas that work in the same range of values that include all possibilities is required.

Unfortunately, none of the available production indexes meets the requirements to compare performance of production in different stages with variable periods.

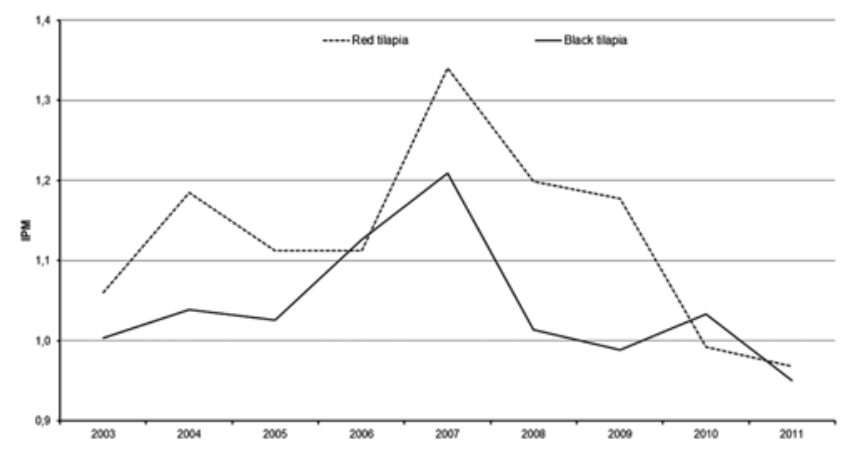

Figure 12. Year evolution of production and management index for black and red tilapia cages.
Therefore, the main advantage is that the PMI provides a standardized value that allows comparing productivity under very variable conditions. In our study, red tilapia had better performance than black tilapia. Nhi and Preston (2012) compared red and black tilapias, and they observed that black tilapia had a better specific growth rate than red tilapia $(3.35 \%$ vs. $3.12 \% / \mathrm{d})$, but survival was worse in black tilapia ( $93 \%$ vs. $98 \%$ ). The use of the PMI combined both components, and it allowed us to carry out better comparisons. For example, an increased productivity for both varieties was observed in 2007 with a progressive decrease until 2011; unfortunately, we have no additional data to discuss this evolution. Further research should be performed to determine the effect of different factors such as husbandry, environmental conditions of the dam, and the health status of tilapia populations.

In conclusion, the absence of a standardized index in tilapia production makes it difficult to compare the performance of different production units and/or different periods. We have proposed a PMI that can be used with this aim in mind. The application of the PMI for 2 tilapia farms showed that this index is consistent and useful for detecting potential handling, environmental, or sanitary problems.

\section{LITERATURE CITED}

Bayot, B., S. Sonnenholzner, X. Ochoa, J. Guerrerro, T. Vera, J. Calderón, I. de Blas, M. P. Cornejo-Grunaue, S. Stern, and F. Ollevier. 2008. An online operational alert system for the early detection of shrimp epidemics at the regional level based on real-time production. Aquaculture 277:164-173. doi:10.1016/j. aquaculture.2008.02.035

Bondad-Reantaso, M. G., and R. P. Subasinghe. 2008. Meeting the future demand for aquatic food through aquaculture: The role of aquatic animal health. In: K. Tsukamoto, T. Kawamura, T. Takeuchi, T. D. Beard, and M. J. Kaiser, editors, Fisheries for global welfare and environment: Memorial book of 5th World Fisheries Congress. Terrapub, Tokyo. p. 197-207.

Dersjant-Li, Y., A. Awati, C. Kromm, and C. Evans. 2014. A direct fed microbial containing a combination of three-strain Bacillus sp. can be used as an alternative to feed antibiotic growth promoters in broiler production. J. Appl. Anim. Nutr. 2:e11. doi:10.1017/ jan.2014.4

Dórea, F. C., B. J. McEwen, W. B. McNab, J. Sanchez, and C. W. Revie. 2013. Syndromic surveillance using veterinary laboratory data: Algorithm combination and customization of alerts. PLoS One 8(12):e82183. doi:10.1371/journal.pone.0082183 
El-Sayed, A.-F. M. 2006. Tilapia culture. CABI Publ., Wallingford, UK. doi:10.1079/9780851990149.0000

Food and Agriculture Organization of the United Nations. 2014. The state of world fisheries and aquaculture: Opportunities and challenges. Food Agric. Organ. U. N., Rome.

Fuller, M. F. 2004. The encyclopedia of farm animal nutrition. CABI Publ., Wallingford, UK. doi:10.1079/9780851993690.0000

Georgiadis, M. P., R. P. Hedrick, T. E. Carpenter, and I. A. Gardner. 2001. Factors influencing transmission, onset and severity of outbreaks due to white sturgeon iridovirus in a commercial hatchery. Aquaculture 194:21-35. doi:10.1016/S0044-8486(00)00503-2

Hedrick, R. P. 1998. Relationships of the host, pathogen, and environment: Implications for diseases of cultured and wild fish populations. J. Aquat. Anim. Health 10:107-111. doi:10.1577/15488667(1998)010<0107:ROTHPA>2.0.CO;2

MacDiarmid, S. C. 2001. Risk analysis in aquatic animal health. In: C. J. Rodgers, editor, Risk analysis in aquatic animal health. World Organ. Anim. Health, Paris.

Nhi, N. H. Y., and T. R. Preston. 2012. Growth of red tilapia (Oreochomis mossambicus) and black tilapia (Oreochomis niloticus) with common carp (Ciprinus carpio) in monoculture and polyculture by using natural feed in ponds fertilized with biodigester effluent. Livest. Res. Rural Dev. 24(7):111.
Sonnenholzner, S., B. Bayot, I. Apolo, T. Vera, X. Ochoa, Z. Cisneros, L. Van Biesen, M. P. Cornejo, and J. Calderón. 2004. Ecuador Develops GIS-Assisted Alert System For Shrimp Farming. Global Aquaculture Advocate. 7(3):72-73.

Sturges, H. 1926. The choice of a class interval. J. Am. Stat. Assoc. 21:65-66. doi:10.1080/01621459.1926.10502161

Subasinghe, R. P. 2005. Epidemiological approach to aquatic animal health management: Opportunities and challenges for developing countries to increase aquatic production through aquaculture. Prev. Vet. Med. 67:117-124. doi:10.1016/j.prevetmed.2004.11.004

Subasinghe, R. P., S. E. McGladdery, and B. J. Hill, editors. 2004. Surveillance and zoning for aquatic animal diseases. FAO Fish. Tech. Pap. No. 451. Food Agric. Organ. U. N., Rome.

Watanabe, W. O., T. M. Losordo, K. Fitzsimmons, and F. Hanley. 2002. Tilapia production systems in the Americas: Technological advances, trends, and challenges. Rev. Fish. Sci. 10:465-498. doi:10.1080/20026491051758

Wendt, A., L. Kreienbrock, and A. Campe. 2015. Zoonotic disease surveillance - Inventory of systems integrating human and animal disease information. Zoonoses Public Health 62(1):61-74. doi:10.1111/zph.12120

World Organisation for Animal Health. 2014. Aquatic animal health code. 17th ed. http://www.oie.int/en/international-standardsetting/aquatic-code/access-online/. (Accessed 20 April 2016.) 